\title{
Research on the transformation path of cigarette consumers' internal quality demand based on AHP and Shapley value decomposition
}

\author{
Lei Yang ${ }^{1}$, Tao Zhang ${ }^{1}$, Yao Yu ${ }^{1}$, Hong Tao Feng ${ }^{1}$, Jia Can $\mathrm{Wu}^{1}$, Yan Qun Xu${ }^{1}$, Hai Juan Wang ${ }^{1}$ and Xue \\ Feng $\mathrm{He}^{* 1}$ \\ ${ }^{1}$ R\&D Center, China Tobacco Yunnan Industrial Co., Ltd. Kunming, Yunnan, 650231, China
}

\begin{abstract}
Consumers' evaluation of cigarette quality directly affects their willingness to repeat purchase. In order to find out the relationship between the consumer evaluation indicator and the quality of cigarette products, to effectively guide the improvement of cigarette manufacturing technology, based on the evaluation standards of the sensory quality of the cigarette industry, the hierarchical structure indicator of attribute elements of cigarette products are established by using the analytic hierarchy process. Through the quantitative investigation of consumers and the investigation of experts, combined with the correlation analysis, the correlation degree between the evaluation indicators of consumers and the design elements of product attributes is verified, and the path is modified and optimized by Shapley value decomposition method. Finally, the transformation path of the internal quality demand of cigarette consumers is completed Build. The establishment of this path can effectively solve the problems of correlation between cigarette sensory quality and cigarette manufacturing technology, as well as the corresponding relationship between cigarette sensory quality and consumer evaluation of cigarette quality indicators. It is of considerable significance to effectively guide the improvement of cigarette product formula and improve consumer satisfaction through consumer evaluation.
\end{abstract}

\section{INTRODUCTION}

For a long time, consumers have a set of their language to evaluate the quality of cigarettes, which is different from the technical indicators of cigarette manufacturing and the evaluation methods of professional cigarette formulators. At present, the sensory quality of cigarettes depends on the layer of cigarette manufacturing technology. The evaluation of cigarette quality by consumers is often closely related to the sensory quality of the cigarette. However, there are many complex factors in cigarette manufacturing technology. Although the tobacco industry has established the relevant sensory quality evaluation standard of cigarettes [1], however, there are few reports on the correlation between the sensory quality of cigarette and cigarette manufacturing technology, and the corresponding relationship between sensory quality of cigarette and consumer evaluation indicator of cigarette quality.

The analytic hierarchy process (AHP) is a relatively mature decision analysis method at present. It introduces the concept of layering to structure complex problems. It is a practical decision analysis method that effectively combines the qualitative judgment and quantitative calculation of decision-makers[2-4]. Through a literature search, AHP has been applied in the establishment of a credit indicator system of the tobacco industry. For example, Zhu Jun [5] put forward some ideas and suggestions on the establishment of credit indicator system of the tobacco industry by using AHP, and made a practical analysis combining with Tianjin tobacco; Zheng Xiaoping et al. [6] put forward a credit evaluation indicator system and corresponding dynamic credit evaluation model of operators, which includes three first-layer indicators and 10-second-layer indicators, by using AHP. By analyzing the characteristics of tobacco monopoly retail operators, the connotation and category of credit, He Ruhan[7] and others applied group decision-making and AHP to construct the credit evaluation indicator system of retail cigarette customers.

Therefore, the purpose of this study is to analyze the relationship between cigarette sensory quality indicator, consumer evaluation indicator, and cigarette manufacturing technology indicator by AHP combined with regression Shapley value decomposition method, and finally complete the construction of the transformation path of cigarette consumers' internal quality demand. From the perspective of the application, it can effectively solve the problems of correlation between cigarette sensory quality and cigarette 
manufacturing technology, as well as the corresponding relationship between cigarette sensory quality and consumer evaluation indicators of cigarette quality, to effectively guide the improvement of cigarette product formula through consumer evaluation and improve consumer satisfaction $[3,4]$.

\section{EXPERIMENTAL MATERIALS AND METHODS}

\section{A. Data source}

This survey adopts the methods of consumer survey and expert survey, using consumer indicators and product attribute design elements (expert technical indicators) for Smoking assessment. Among them, the expert survey invited 10 product evaluation experts from Yunnan China Tobacco Technology Center, and the consumer survey recruited 133 heavy cigarette consumers from seven regions of the country (smoking age of 2 years and above, daily average smoking amount of more than ten cigarettes). The survey covers seven regions and two cities in each region, totaling 14 cities; each city has ten questionnaires, totaling 140, and each city has one backup questionnaire. The final number of questionnaires is 154 , and the actual valid questionnaire is 133 , the qualified rate is $86.3 \%, 144$ verification questionnaires, qualified 133 , the qualified rate is $92.4 \%$. In terms of test product selection, the top 40 cigarette products in China in 2017 were selected as the research objects, covering one, two, three, four different price categories, and different price levels of cigarette products. See table 1-2 for sample distribution.

\section{B. Indicator collection}

According to the technical standards of Yunnan China tobacco products enterprises[1], concerning the suggestions of process experts, and combined with the sensory quality evaluation standards of cigarettes established by the tobacco industry, the design elements of the attributes of Yunnan China tobacco products are preliminarily obtained. After expert workshop discussion, the product attribute design elements are divided into two layers: design-layer (9 indicators for product formulation and process improvement) and result-layer (21 indicators for sensory quality evaluation), As shown in Table 3.

TABLE1 DISTRIBUTION OF QUANTITATIVE SAMPLES

$\mathrm{N}=133$

\begin{tabular}{|c|c|c|c|c|c|c|c|}
\hline region & East China & North China & South China & $\begin{array}{c}\text { southwest } \\
\text { China }\end{array}$ & $\begin{array}{c}\text { Northwest } \\
\text { China }\end{array}$ & $\begin{array}{c}\text { northeast } \\
\text { China }\end{array}$ & Central China \\
\hline City & Shanghai & Beijing & Guangzhou & Chengdu & Xi'an & Shenyang & Wuhan \\
\hline sample size & 11 & 10 & 9 & 11 & 8 & 10 & 8 \\
\hline City & Ningbo & Baoding & Shenzhen & Kunming & Lanzhou & Harbin & Zhengzhou \\
\hline sample size & 8 & 11 & 8 & 10 & 9 & 11 & 9 \\
\hline total & 19 & 21 & 17 & 21 & 17 & 21 & 17 \\
\hline male & 16 & 18 & 14 & 18 & 14 & 18 & 15 \\
\hline female & 3 & 3 & 3 & 3 & 3 & 3 & 2 \\
\hline rate/\% & $14.29 \%$ & $15.79 \%$ & $12.78 \%$ & $15.79 \%$ & $12.78 \%$ & $15.79 \%$ & $12.78 \%$ \\
\hline
\end{tabular}

TABLE2 PRICE CATEGORY AND TAR CONTENT DISTRIBUTION OF 40 TEST PRODUCTS

\begin{tabular}{|c|c|c|c|c|}
\hline Cigarette price & $\begin{array}{c}\text { Number of } \\
\text { products }\end{array}$ & Price class definition & Tar yield & Number of products \\
\hline $\begin{array}{l}\text { Price class I } \\
\text { cigarette }\end{array}$ & 10 & Retail price is more than 180 yuan/piece & $<=8 \mathrm{mg}$ & 8 \\
\hline $\begin{array}{l}\text { Price class II } \\
\text { cigarette }\end{array}$ & 10 & Retail price is 130 yuan / piece (including) - 180 yuan / piece & $9-10 \mathrm{mg}$ & 13 \\
\hline $\begin{array}{l}\text { Price } \\
\text { classIIIcigarettes }\end{array}$ & 13 & $\begin{array}{l}\text { The retail price is } 60 \text { yuan / piece (including) - } 130 \text { yuan / } \\
\text { piece }\end{array}$ & $11-12 \mathrm{mg}$ & 9 \\
\hline $\begin{array}{l}\text { Price } \\
\text { classIVcigarettes }\end{array}$ & 7 & $\begin{array}{l}\text { The retail price is } 30 \text { yuan / piece (including) - } 60 \text { yuan / } \\
\text { piece }\end{array}$ & & \\
\hline $\begin{array}{c}\text { Price } \\
\text { classVcigarettes }\end{array}$ & 0 & Retail price is less than 30 yuan/piece & & \\
\hline
\end{tabular}

TABLE 3. PRODUCT ATTRIBUTE ELEMENTS

\begin{tabular}{|c|l|}
\hline $\begin{array}{c}\text { Design-layer } \\
\text { (9 indicators) }\end{array}$ & $\begin{array}{l}\text { X1: cut tobacco, X2: tobacco leaves, X3: Spice formula, X4: flavor formula, X5: technology of threshing and redrying, X6: } \\
\text { technology of tobacco manufacture process, X7: Physical indicators of cigarettes, X8: cigarette material, } \\
\text { X9: packaging material }\end{array}$ \\
\hline Result-layer & Y1: odor, Y2: packet opening aroma, Y3: smoke density, Y4: impact, Y5: softness, Y6: cigarette smoke concentration,Y7: \\
(21 indicators) & smooth, Y8: diffusivity, Y9: abundance, Y10: aroma quality, Y11: aroma volume, Y12: mellowness, \\
& Y13: harmony, \\
& Y14: offensive taste, Y15: irritancy in nasal, Y16: irritancy in oral, Y17: irritancy in throat, Y18: cleanness, \\
& Y19: salivation, Y20: oral comfort, Y21: after taste \\
\hline
\end{tabular}


Remarks: cut tobacco include: cut stem, Adding proportion of expanded tobacco, Proportion of upper, middle and lower leaf, Adding proportion of Reconstituted tobacco

tobacco leaves include: leaf grade

Physical indicators of cigarettes include : cigarette length, Circumference, Weight, draw resistance, Hardness, dust content, Moisture content,

Total ventilation rate

cigarette material include: Filter Rod, printing ink, Cigarette paper, tipping paper, plug wrap paper

packaging material include: Inner-frame paper,outer-frame paper, trademark, carton packing, printing ink

This study uses the results of previous studies for reference. It adopts a set of optimized evaluation indicator system of internal attributes of consumer cigarettes that can be used in the study [8], including 16 consumer indicators, as the consumer evaluation indicator in the exploration and research of the transformation path of internal quality demand of consumers (see table 4).

TABLE 4. CONSUMER EVALUATION INDICATORS (16)

\begin{tabular}{|c|c|c|}
\hline Variable & Indicator title & Indicator description \\
\hline $\mathrm{Z1}$ & $\begin{array}{l}\text { pure flavor/aroma of } \\
\text { tobacco }\end{array}$ & It smells of tobacco flavor, no flavors or additives. \\
\hline $\mathrm{Z2}$ & unique/special odor & The smell has a unique fragrance, which is distinctive and distinguishable. \\
\hline $\mathrm{Z3}$ & strong \& light odor & A firm or light aroma in the process of smelling \\
\hline $\mathrm{Z4}$ & oral comfort & The cigarette has a soft entrance, no bitterness, no irritation of the tongue. \\
\hline $\mathrm{Z5}$ & mouth moist & There is no feeling of dryness, dryness, and burning in the mouth during the whole suction process. \\
\hline Z6 & Oral richness sensation & When smoking, the smoke in the mouth is full and sufficient. \\
\hline $\mathrm{Z7}$ & stability & When smoking, the feeling is consistent from the first to the last. \\
\hline Z8 & throat comfort & When smoke enters the throat, there is no burning or hot feeling in the throat. \\
\hline Z9 & Softness, Smooth and grainy & When the smoke is inhaled, the throat feels soft and delicate, without the sense of particles. \\
\hline $\mathrm{Z10}$ & smooth & The smoke can enter the throat smoothly, and smoking is not difficult. \\
\hline Z11 & impact & The smoke concentration is moderate, and it can be easily swallowed, not top the throat. \\
\hline Z12 & nasal comfort & The intensity of the burning sensation of cigarettes on the nose when smoke enters the nose \\
\hline Z13 & abundance & When the smoke enters the nasal cavity, it feels luxurious, harmonious, and layered. \\
\hline Z14 & aftertaste & It is not bitter or spicy after smoking, and it is sweet again. \\
\hline Z15 & aftertaste cleanness & No astringency or coating feeling in the mouth after smoking \\
\hline Z16 & $\begin{array}{l}\text { mouth moist sensation after } \\
\text { smoking }\end{array}$ & The mouth does not feel dry after smoking, and the mouth is moist and cannot produce phlegm. \\
\hline
\end{tabular}

\section{Analysis method}

The research on the transformation path of internal quality demand of cigarette consumers is completed in two stages, First of all, by using the AHP method $[3,4]$, let experts evaluate the relative importance of different layers of indicators. Establish the preliminary relationship between design-layer indicators, result-layer indicators, and consumer evaluation indicators in product attribute indicators, and establish the weight of each indicator link. Then, through the results of consumer quantitative research and expert research data, combined with correlation analysis and Shapley value decomposition method based on regression equation, verify the specific relevance of consumer evaluation indicator, design-layer indicator, and result-layer indicator, and complete the modification and optimization of the transformation path of cigarette consumers' internal quality demand.

1) Preliminary construction of the transformation path of cigarette consumers' internal quality demand

\section{a) Constructing a judgment matrix}

The indicators of the same layer were listed in the row and column of the judgment matrix, and nine smoking evaluation experts of Yunnan China Tobacco Technology Center and were organized to use the rotation scoring method to compare the two scores. See Table 5.

In order to show the importance of each element in the matrix quantitatively, the matrix judgment scale (1-9 scale method) [9] is introduced as the scoring system, and the scale meaning is shown in Table 6 below.

TABLE 5. AN EXAMPLE OF JUDGMENT MATRIX SCORING

\begin{tabular}{|c|c|c|c|c|}
\hline $\begin{array}{c}\text { j factor } \\
\text { I factor }\end{array}$ & $\begin{array}{c}\text { cut } \\
\text { tobacco }\end{array}$ & $\begin{array}{c}\text { tobacco } \\
\text { leaves }\end{array}$ & $\begin{array}{c}\text { flavor } \\
\text { formula }\end{array}$ & $\begin{array}{c}\text { flavor } \\
\text { formula }\end{array}$ \\
\hline cut tobacco & 1 & & & \\
\hline tobacco leaves & & 1 & & \\
\hline Spice formula & & & 1 & \\
\hline flavor formula & & & & 1 \\
\hline
\end{tabular}

TABLE 6 JUDGMENT MATRIX SCORING SYSTEM

\begin{tabular}{|l|l|}
\hline Scale & Meaning \\
\hline $\mathbf{1}$ & Represents the same importance of two elements \\
\hline $\mathbf{3}$ & $\begin{array}{l}\text { Indicates that the former is slightly more important than the } \\
\text { latter }\end{array}$ \\
\hline $\mathbf{5}$ & The former is many valuable than the latter \\
\hline $\mathbf{7}$ & The former is more important than the latter \\
\hline $\mathbf{9}$ & The former is most important than the latter \\
\hline $\mathbf{2 , 4 , 6 , 8}$ & $\begin{array}{l}\text { Represents the intermediate value of the above adjacent } \\
\text { judgments }\end{array}$ \\
\hline Reciprocal: if the importance ratio of element i to element $\mathrm{j}$ is $\mathrm{A}_{\mathrm{ij}}$, then \\
\hline
\end{tabular}


the importance ratio of element $\mathrm{j}$ to element $\mathrm{i}$ is $\mathrm{A}_{\mathrm{ii}}=1 / \mathrm{a}_{\mathrm{i}}$

For the factors that need to be compared, if they are considered as equally important, the importance ratio is $1: 1$; if they are considered as powerfully necessary, the ratio is $9: 1$, and the intermediate value of $6: 1$ can also be taken. By comparing the two values, fill in the values, and arrange them into a judgment matrix (the judgment matrix is a positive and negative matrix whose diagonal product is 1 ).

\section{b) Conduct consistency inspection}

After constructing the judgment matrix, the project team calculates the maximum eigenvalue and its corresponding eigenvector for each pair of comparison matrix and uses the consistency indicator, random consistency indicator, and consistency ratio to test the consistency. If the test is passed, the eigenvector (after normalization) is the weight vector; if not, the pairwise comparison matrix needs to be reconstructed.

The judgment matrix is usually inconsistent, but in order to use its eigenvector corresponding to the characteristic root as the weight vector of the factor to be compared, the degree of inconsistency should be within the allowable range. How to determine the scope? Generally, the following three indicators are used to determine the scope: consistency indicator $\mathrm{Ci}$, random consistency indicator RI, and consistency ratio CR.

i. consistency indicator $\mathrm{CI}$

$$
\mathrm{CI}=(\lambda-n) /(n-1)
$$

In Formula(1), When $\mathrm{CI}=0$, the judgment matrix(a)is entirely consistent; The more significant the CI, the less consistent the judgment matrix(a)..$\lambda$ is the maximum positive eigenvalue of a.

In the above formula, when $\mathrm{CI}=0$, the judgment matrix has complete consistency; otherwise, the more significant $\mathrm{Ci}$, the worse the consistency of the judgment matrix.

ii. random consistency indicator RI

iii. consistency ratio $\mathrm{Cr}$

- The consistency ratio is usually used to determine the allowable range of a's inconsistency.

\section{$\mathrm{CR}=\mathrm{CI} / \mathrm{RI}$}

In Formula(2), When $\mathrm{CR}<0.1$ and the inconsistency of matrix (a) is within the allowable range, the eigenvector of the judgment matrix (a) can be used as the weight vector.

- Comparing CI with RI can test whether the judgment matrix has satisfactory consistency.

- If $\mathrm{CR}<0.1$, the consistency of judgment matrix is satisfactory;

- If $\mathrm{Cr} \geq 0.1$, the judgment matrix shall be adjusted until it is satisfactory.

\section{c) Calculate weight vector}

After passing the consistency test, it is necessary to use the judgment matrix to calculate the weight (weight coefficient) of each factor to the target layer. The calculation process is as follows:

i. Normalize each row of vectors of a ii. Sum the normalized vectors bylines

iii. normalize the sum post vector, i.e., approximate characteristic root (weight vector)

iv. calculate the approximate value $\lambda$ of the maximum eigenvalue

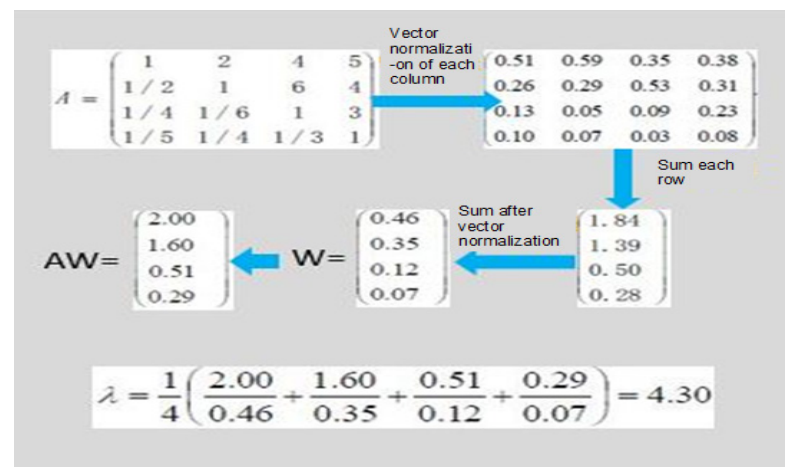

FIGURE 1. EXAMPLE OF CALCULATING SINGLE SORT WEIGHT VECTOR

d) Relevance verification of transformation path of cigarette consumers' internal quality demand

First of all, based on the quantitative survey results of consumers and experts, the average value of overall evaluation scores (scoring indicators) of consumers and experts on products is used as the original data of correlation analysis to explore the correlation between cigarette indicators and consumer satisfaction. The correlation results are obtained by SPSS software. Secondly, in order to further verify the relationship between expert technical indicators (Result-layer indicators) and consumer indicator system, the Shapley value decomposition method based on the regression equation is used to determine the importance of expert technical indicators to consumer indicators. The contribution degree of each expert indicator is determined by calculating the change of $\mathrm{R}$ when it is included in the model and not included in the model. Pearson correlation coefficient, as a simple correlation coefficient, is used to measure the linear relationship between two variables. The larger the correlation coefficient, the stronger the linear relationship between variables. The calculation formula is:

$$
\begin{aligned}
& r(X, Y)=\frac{\operatorname{cov}(X, Y)}{\sqrt{\operatorname{var}(X) \operatorname{var}(Y)}} \\
& r=\frac{\sum_{1}^{n}\left(X_{i}-\bar{X}\right)\left(Y_{i}-\bar{Y}\right)}{\sqrt{\sum_{1}^{n}\left(X_{i}-\bar{X}\right)^{2} \sum_{1}^{n}\left(Y_{i}-\bar{Y}\right)^{2}}}
\end{aligned}
$$

The Shapley value decomposition method based on the regression equation calculates the contribution degree of each independent variable after calculating all possible variable combinations. Therefore, compared with ordinary linear regression, the Shapley value decomposition method can resolve the collinearity between independent variables, and more accurately explain the importance of expert indicators for consumer indicators in this project. Where the Shapley value of each variable is calculated as follows:

$$
\mathrm{S} V_{j}=\sum_{k} \sum_{i} \frac{k !(n-k-1) !}{n !}\left[v\left(M_{i j}\right)-v\left(M_{i j(-j)}\right)\right]
$$


$v\left(M_{i \mid j}\right)$ is the $\mathrm{r} 2$ when a model $\mathrm{i}$ contains variable $\mathrm{j}$, $v\left(M_{i \mid j(-j)}\right)$ is the $\mathrm{r} 2$ when a model i does not contain variable $\mathrm{j}, v\left(M_{i \mid j}\right)-v\left(M_{i \mid j(-j)}\right)$ is the change of $\mathrm{r} 2$ when $\mathrm{j}$ variable is included in the model, and $\mathrm{j}$ variable is not included in the model, $\mathrm{n}$ is the total number of variables, $\mathrm{k}$ is the total number of variables in the model when $\mathrm{j}$ variable is not included, $\frac{k !(n-k-1) !}{n !}$ is the weight.

\section{Results AND ANALYSIS}

A. Preliminary construction of the transformation path of cigarette consumers' internal quality demand

1) Correlation results of result-layer and design-layer

The correlation results of the result-layer and design-layer were shown in the following table9-10.

TABLE 7 DISCUSSION RESULTS OF CORRELATION BETWEEN RESULT- LAYER AND DESIGN-LAYER

\begin{tabular}{|c|c|c|c|c|c|c|c|c|c|c|c|}
\hline \multirow{2}{*}{ Serial number } & \multirow{2}{*}{ Result-layer } & \multicolumn{9}{|c|}{ Design-layer (influence indicators) } & \multirow{2}{*}{ Number of relevant indicators } \\
\hline & & $\mathrm{X} 1$ & $\mathrm{X} 2$ & $\mathrm{X} 3$ & $\mathrm{X} 4$ & $\mathrm{X} 5$ & X6 & $\mathrm{X} 7$ & $\mathrm{X} 8$ & $\mathrm{X} 9$ & \\
\hline 1 & Y1 & & & $\bullet$ & $\bullet$ & & & & $\bullet$ & & 3 \\
\hline 2 & $\mathrm{Y} 2$ & & & $\bullet$ & $\bullet$ & & & & $\bullet$ & & 3 \\
\hline 3 & Y3 & $\bullet$ & $\bullet$ & $\bullet$ & $\bullet$ & $\bullet$ & $\bullet$ & $\bullet$ & $\bullet$ & & 8 \\
\hline 4 & Y4 & $\bullet$ & $\bullet$ & & & & & $\bullet$ & $\bullet$ & & 4 \\
\hline 5 & Y5 & $\bullet$ & $\bullet$ & $\bullet$ & $\bullet$ & $\bullet$ & $\bullet$ & $\bullet$ & $\bullet$ & & 8 \\
\hline 6 & Y6 & $\bullet$ & $\bullet$ & $\bullet$ & $\bullet$ & $\bullet$ & $\bullet$ & $\bullet$ & $\bullet$ & & 8 \\
\hline 7 & $\mathrm{Y} 7$ & $\bullet$ & $\bullet$ & $\bullet$ & $\bullet$ & $\bullet$ & $\bullet$ & $\bullet$ & $\bullet$ & & 8 \\
\hline 8 & Y8 & $\bullet$ & $\bullet$ & $\bullet$ & $\bullet$ & & $\bullet$ & & $\bullet$ & & 6 \\
\hline 9 & Y9 & $\bullet$ & $\bullet$ & $\bullet$ & $\bullet$ & & $\bullet$ & & $\bullet$ & & 6 \\
\hline 10 & $\mathrm{Y} 10$ & $\bullet$ & $\bullet$ & $\bullet$ & $\bullet$ & $\bullet$ & $\bullet$ & $\bullet$ & $\bullet$ & & 8 \\
\hline 11 & Y11 & - & $\bullet$ & $\bullet$ & $\bullet$ & $\bullet$ & $\bullet$ & - & $\bullet$ & & 8 \\
\hline 12 & Y12 & $\bullet$ & $\bullet$ & $\bullet$ & $\bullet$ & $\bullet$ & $\bullet$ & & & & 6 \\
\hline 13 & Y13 & $\bullet$ & $\bullet$ & $\bullet$ & $\bullet$ & & & & & & 4 \\
\hline 14 & Y14 & $\bullet$ & $\bullet$ & $\bullet$ & $\bullet$ & $\bullet$ & $\bullet$ & & $\bullet$ & $\bullet$ & 8 \\
\hline 15 & Y15 & $\bullet$ & $\bullet$ & $\bullet$ & $\bullet$ & $\bullet$ & $\bullet$ & $\bullet$ & $\bullet$ & & 8 \\
\hline 16 & Y16 & $\bullet$ & $\bullet$ & $\bullet$ & $\bullet$ & $\bullet$ & $\bullet$ & $\bullet$ & $\bullet$ & & 8 \\
\hline 17 & Y17 & $\bullet$ & $\bullet$ & $\bullet$ & $\bullet$ & $\bullet$ & $\bullet$ & $\bullet$ & $\bullet$ & & 8 \\
\hline 18 & $\mathrm{Y} 18$ & $\bullet$ & $\bullet$ & $\bullet$ & $\bullet$ & $\bullet$ & $\bullet$ & & & & 6 \\
\hline 19 & Y19 & $\bullet$ & $\bullet$ & $\bullet$ & $\bullet$ & $\bullet$ & $\bullet$ & & & & 6 \\
\hline 20 & $\mathrm{Y} 20$ & $\bullet$ & $\bullet$ & $\bullet$ & $\bullet$ & $\bullet$ & $\bullet$ & & & & 6 \\
\hline 21 & Y21 & $\bullet$ & $\bullet$ & $\bullet$ & $\bullet$ & $\bullet$ & $\bullet$ & & & & 6 \\
\hline
\end{tabular}

2) Weight calculation based on $A H P$

Through the collective discussion of the experts, collect their scores and opinions. Because the importance of each expert participating in the workshop is equal, there is no need to assign the importance of the expert.
When calculating the weight, select the average value of the expert weight result of the judgment matrix constructed by the expert through the consistency test as the final weight of the transformation path, as shown in the following table9-10.

TABLE 8 DISCUSSION RESULTS OF CORRELATION BETWEEN CONSUMER EVALUATION INDICATORS AND RESULT_LAYER

\begin{tabular}{|c|c|c|c|}
\hline Variable & Consumer indicators & Result-layer ( 21 expert indicators in total) & $\begin{array}{l}\text { Number of } \\
\text { relevant } \\
\text { indicators }\end{array}$ \\
\hline $\mathrm{Z1}$ & $\begin{array}{c}\text { pure flavor/ aroma of } \\
\text { tobacco }\end{array}$ & Odor, packet opening aroma & 2 \\
\hline $\mathrm{Z} 2$ & unique / special odor & odor, packet opening aroma & 2 \\
\hline $\mathrm{Z3}$ & strong \& light odor & odor, packet opening aroma & 2 \\
\hline $\mathrm{Z4}$ & oral comfort & Softness, smooth, mellowness, irritancy in oral, cleanness, salivation, oral comfort, after taste & 8 \\
\hline $\mathrm{Z} 5$ & mouth moist & smooth, irritancy in oral, cleanness, salivation, oral comfort & 5 \\
\hline Z6 & Oral richness sensation & smoke density, cigarette smoke concentration & 2 \\
\hline $\mathrm{Z7}$ & stability & $\begin{array}{l}\text { smoke density, impact, softness, cigarette smoke concentration, smooth, diffusivity, abundance, aroma } \\
\text { quality, aroma volume, mellowness, harmony, offensive taste, irritancy in nasal, irritancy in oral, irritancy in } \\
\text { throat, cleanness, salivation, oral comfort, after taste }\end{array}$ & 19 \\
\hline Z8 & throat comfort & impact, softness, irritancy in the throat & 3 \\
\hline Z9 & $\begin{array}{l}\text { Softness, Smooth and } \\
\text { grainy }\end{array}$ & impact, softness, smooth, irritancy in the throat & 4 \\
\hline $\mathrm{Z} 10$ & smooth & impact, softness, irritancy in the throat & 3 \\
\hline
\end{tabular}




\begin{tabular}{ccl}
\hline Z11 & impact & smoke density, impact, softness, irritancy in throat \\
Z12 & nasal comfort & softness, smooth, mellowness, irritancy in nasal \\
Z13 & abundance & abundance, aroma quality, aroma volume, mellowness, harmony \\
Z14 & aftertaste & cleanness, salivation, oral comfort, after taste \\
Z15 & aftertaste cleanness & cleanness, oral comfort \\
Z16 & mouth moist sensation & salivation, oral comfort, after taste \\
\hline
\end{tabular}

TABLE 9 TRANSFORMATION PATH CONSTRUCTION RESULTS FROM THE RESULT-LAYER TO THE DESIGN-LAYER

\begin{tabular}{|c|c|c|c|c|c|c|c|c|c|c|c|c|c|c|c|c|c|c|c|c|c|}
\hline $\begin{array}{l}\text { Experts } \\
\text { Fyctor } \\
\text { importance } \\
\text { (weight) }\end{array}$ & Y1 & Y2 & Y3 & Y4 & Y5 & Y6 & Y7 & Y8 & Y9 & Y10 & Y11 & Y12 & Y13 & Y14 & Y15 & Y16 & Y17 & Y18 & Y19 & Y20 & Y21 \\
\hline $\mathrm{X} 1$ & - & - & 0.27 & 0.42 & 0.19 & 0.17 & 0.15 & 0.2 & 0.21 & 0.16 & 0.19 & 0.2 & 0.17 & 0.2 & 0.22 & 0.2 & 0.2 & 0.21 & 0.22 & 0.18 & 0.18 \\
\hline $\mathrm{X} 2$ & - & - & 0.23 & 0.41 & 0.14 & 0.21 & 0.16 & 0.25 & 0.24 & 0.18 & 0.19 & 0.25 & 0.16 & 0.21 & 0.21 & 0.18 & 0.19 & 0.25 & 0.23 & 0.22 & 0.21 \\
\hline $\mathrm{X} 3$ & 0.22 & 0.19 & 0.1 & - & 0.15 & 0.15 & 0.19 & 0.15 & 0.2 & 0.19 & 0.15 & 0.21 & 0.32 & 0.18 & 0.15 & 0.17 & 0.17 & 0.21 & 0.21 & 0.21 & 0.24 \\
\hline $\mathrm{X} 4$ & 0.57 & 0.59 & 0.06 & - & 0.15 & 0.15 & 0.14 & 0.13 & 0.18 & 0.19 & & 0.16 & 0.35 & 0.14 & 0.14 & 0.15 & 0.15 & 0.16 & 0.17 & 0.18 & 0.18 \\
\hline X5 & - & - & 0.06 & - & 0.08 & 0.07 & 0.09 & - & - & 0.08 & 0.06 & 0.09 & - & 0.1 & 0.08 & 0.08 & 0.09 & 0.09 & 0.09 & 0.1 & 0.09 \\
\hline X6 & - & - & 0.06 & - & 0.1 & 0.07 & 0.11 & 0.12 & 0.08 & 0.09 & 0.09 & 0.09 & - & 0.09 & 0.09 & 0.09 & 0.09 & 0.08 & 0.08 & 0.1 & 0.1 \\
\hline $\mathrm{X} 7$ & - & - & 0.04 & 0.09 & 0.04 & 0.04 & 0.05 & - & - & 0.03 & 0.04 & - & - & - & 0.05 & 0.04 & 0.04 & - & - & - & - \\
\hline $\mathrm{X} 8$ & 0.2 & 0.22 & 0.17 & 0.19 & 0.15 & 0.13 & 0.11 & 0.14 & 0.09 & 0.07 & 0.15 & - & - & 0.05 & - & 0.07 & 0.07 & - & - & - & - \\
\hline X9 & - & - & - & - & - & - & - & - & - & - & - & - & - & 0.03 & - & - & - & - & - & - & - \\
\hline
\end{tabular}

TABLE 10 CONSTRUCTION RESULTS OF CONVERSION PATH FROM CONSUMER INDICATORS TO THE RESULT-LAYER INDICATORS

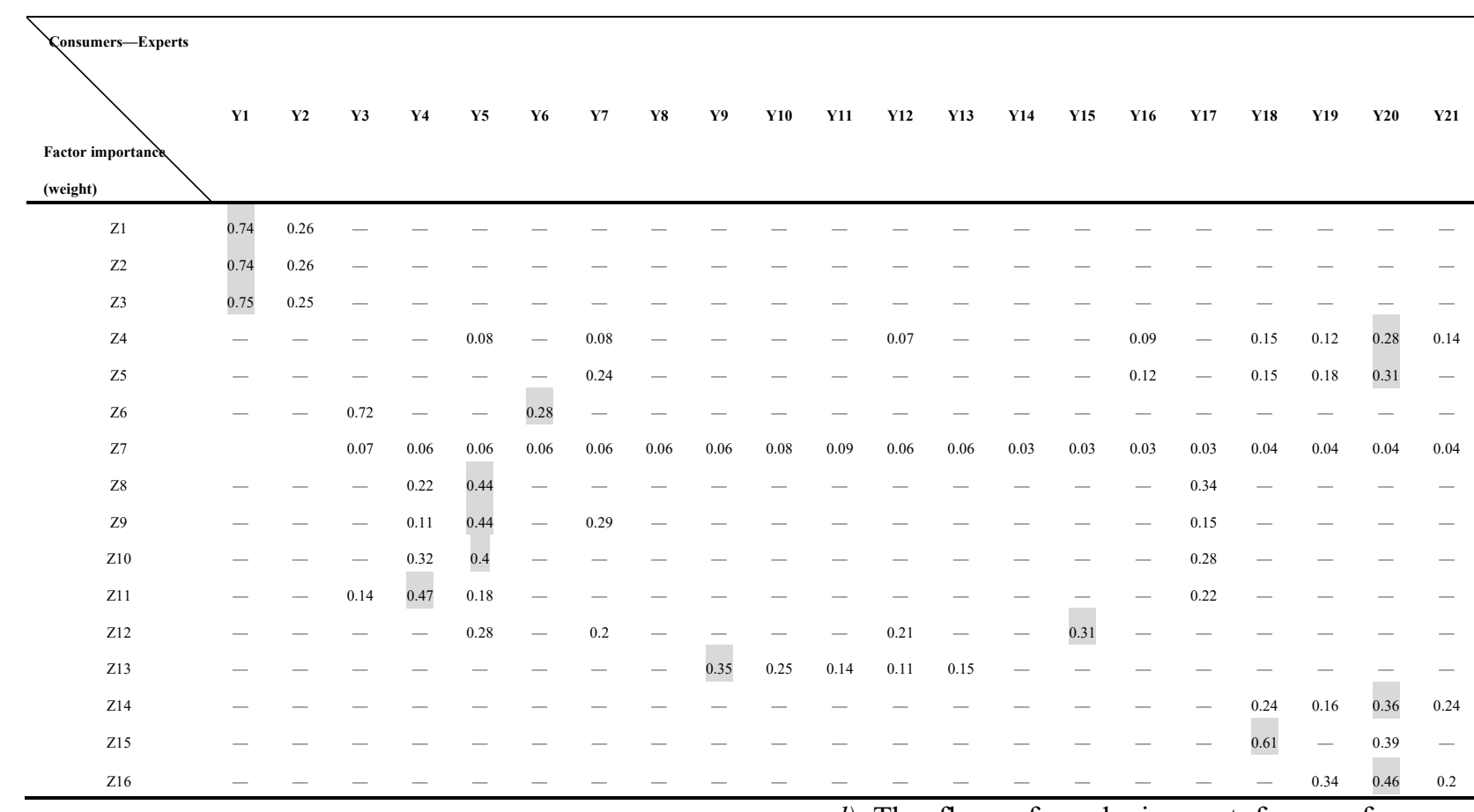

From table 9, it can be concluded that the indicators of different design layers are different from those of their related result layers, accurately as follows:

a) The tobacco leaves have a high correlation with the indicators of smoke density, diffusivity, abundance, aroma volume, mellowness, offensive taste, cleanness, salivation, and oral comfort;

b) The cut tobacco was highly correlated with smoke density, impact, softness, irritancy in nasal, irritancy in oral, and irritancy in throat;

c) The Spice formula has the most significant contribution to the smooth and after taste. d) The flavor formula is most famous for aroma quality, harmony, odor, and packet opening aroma.

From table 10, it can be concluded that different consumer indicators and their related result-layer indicators are different, accurately as follows:

a) In terms of pure flavor/ aroma of tobacco, unique/special odor, and strong \& light odor, odor, and packet opening aroma are related factors, among which the importance of odor is the highest;

b) The expert indicators related to oral comfort include oral comfort, cleanliness, aftertaste, salivation, irritancy in oral, softness, smooth, and mellowness, of which oral comfort is the most important; 
c) For the degree of mouth moist, oral comfort, smooth, salivation, cleanliness, and irritancy in oral are related indicators, among which oral comfort is the most important factor;

d) The degree of fullness of the mouth is related to the concentration and concentration of flue gas, of which the concentration of flue gas is the most important.

e) The stability is affected by various factors and distributed evenly. The relevant indicators include aroma quality, cleanliness, softness, mellowness, aftertaste, offensive taste, oral comfort, salivation, irritancy in nasal, impact, irritancy in throat, irritancy in oral, cigarette smoke concentration, smooth, harmony, abundance, diffusivity, and aroma volume, of which aroma volume is the essential factor.

f) The indicators related to throat comfort and smooth are softness, irritancy in throat and impact, of which softness is the most important;

g) For the Softness, Smooth and grainy, softness, smooth, irritancy in throat and impact are related factors, of which softness is the most important;

h) The indicators related to impact include impact, irritancy in throat, softness, and smoke density, and impact is the most important. i) Irritancy in nasal, softness, mellowness and smooth are the factors related to nasal comfort;

j) The essential factors for abundance are abundance, aroma quality, harmony, aroma volume, and mellowness, among which significantly contributes the most to the abundance.

k) The related factors of after taste sweetness include oral comfort, cleanliness, aftertaste, and salivation, and oral comfort is the most important factor;

l) The factors related to the aftertaste cleanness are cleanliness and oral comfort, of which cleanliness is the most important;

$m$ ) For the degree of mouth moist sensation after smoking, oral comfort, salivation, and aftertaste are related factors, and the essential level of oral comfort is the highest.

3) preliminary construction results of transformation path from consumer evaluation indicator to product attribute design element

Based on the above results, we connect the indicators with relevance in consumer indicators, result-layer indicators, and design-layer indicators. We can initially build the transformation path from consumer indicators to product attribute elements, as shown in Figure 2 and figure 3 .

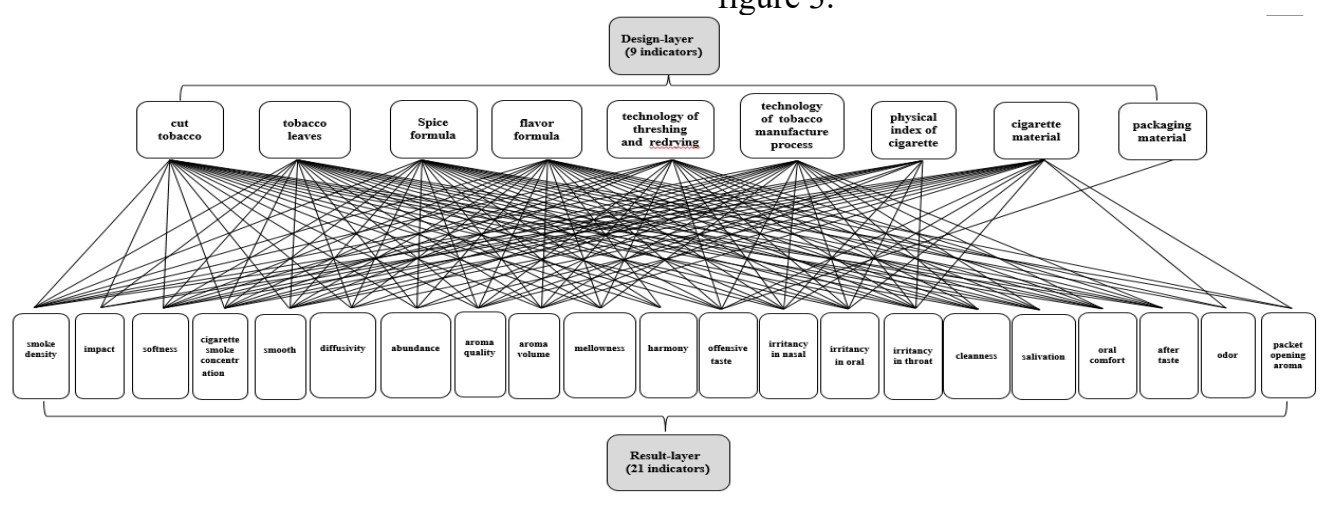

FIGURE 2. CONVERSION PATH FROM DESIGN-LAYER INDICATORS TO RESULT-LAYER INDICATORS

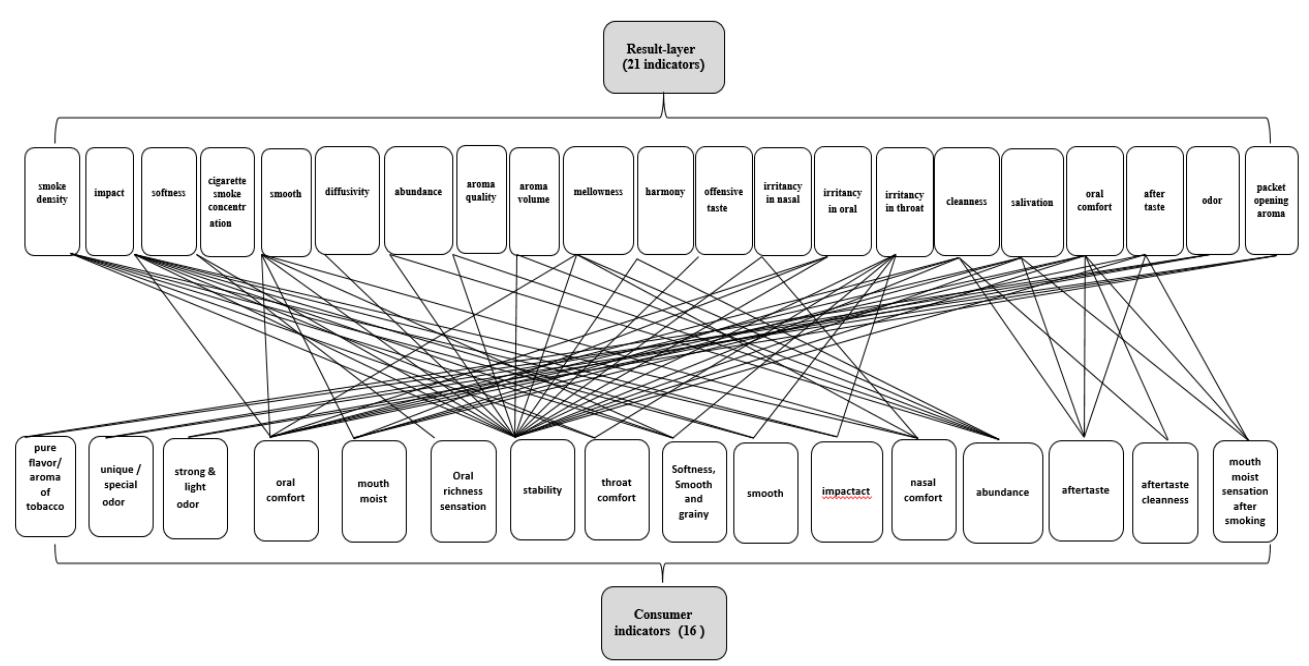

FIGURE 3. TRANSFORMATION PATH FROM CONSUMER INDICATORS TO EXPERT TECHNICAL INDICATORS

As a single indicator may correspond to multiple expert technical indicators, resulting in multiple transformation paths, this paper selects the indicators with the highest average correlation for connection from the transformation paths from the result-layer to the design- layer, and from the transformation paths from 
the consumer indicators to the expert technical indicators, and finally constructs a relatively simplified path model diagram. See Figure 4 below

According to the results of the path map, the following conclusions can be drawn:

a) In the design-layer, the "tobacco formula" is most closely related to the indicators of the result-layer, especially with the "cleanliness," "mellowness" and "diffusivity"; the "cut tobacco" is also closely related to multiple indicators of the result-layer, among which the " impact" is strongly related.

b) The results showed that the "softness" in the layer was most related to the consumer indicator, especially the "throat comfort" and " Softness, Smooth and grainy."

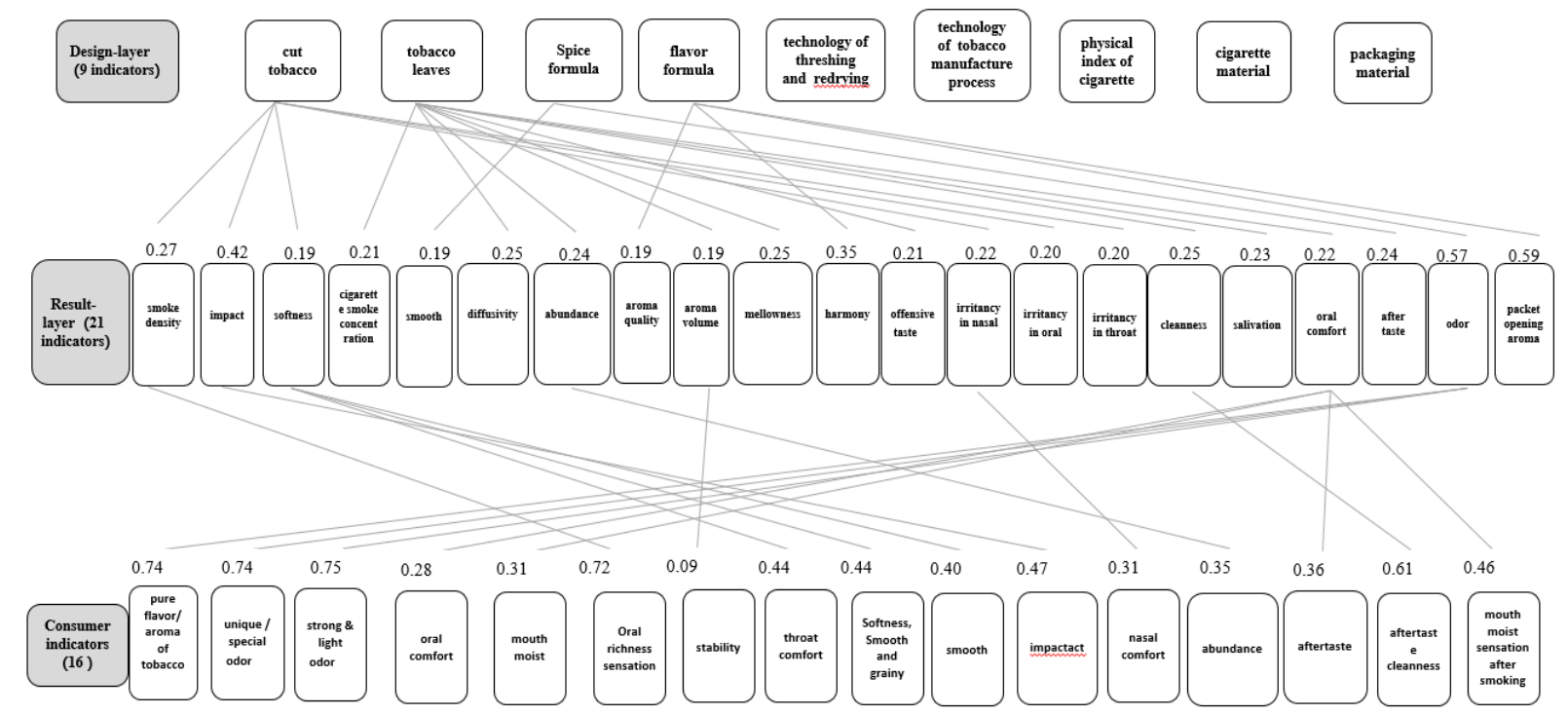

FIGURE 4. TRANSFORMATION PATH CHART: DESIGN-LAYER -> RESULT-LAYER -> CONSUMER (ONLY THE HIGHEST AVERAGE CORRELATION INDICATOR IS SELECTED) 
B. correlation verification results of the transformation path of cigarette consumers' internal quality demand

From table 11, it can be seen that the correlation between each result-layer indicator and consumer indicator is generally high, most of the results are above 0.7 , and the results are significant, indicating that the result-layer indicator and consumer indicator are highly correlated.

Table 11 Pearson Correlation anal ysis results

\begin{tabular}{|c|c|c|c|c|c|c|c|c|c|c|c|c|c|c|c|c|c|c|c|c|c|}
\hline $\begin{array}{l}\text { Pearson } \\
\text { correlation }\end{array}$ & Y1 & Y2 & Y3 & Y4 & Y5 & Y6 & Y7 & Y8 & Y9 & Y10 & Y11 & Y12 & Y13 & Y14 & Y15 & Y16 & Y17 & Y18 & Y19 & Y20 & Y21 \\
\hline Z1 & $.736^{* *}$ & $.793^{* *}$ & $.648^{* 4}$ & $.870^{* *}$ & $.872^{* *}$ & $.870^{* 4}$ & $.860^{* *}$ & $.809^{* *}$ & $.830^{* *}$ & $.892^{* *}$ & $.759^{* *}$ & $.871^{* *}$ & $.833^{* 4}$ & $.873^{* *}$ & $.868^{* *}$ & $.852^{* *}$ & $.854^{* *}$ & $.884^{* *}$ & $.873^{* *}$ & $.882^{* *}$ & $.876^{4 *}$ \\
\hline $\mathrm{Z} 2$ & $.771^{* *}$ & $.812^{* *}$ & $.643^{* *}$ & $.872^{* *}$ & $.897^{* *}$ & $.876^{* *}$ & $.880^{* *}$ & $.835^{* *}$ & $.846^{* *}$ & $.922^{* *}$ & $.771^{* *}$ & $.895^{* *}$ & $.865^{* *}$ & $.910^{* *}$ & $.885^{* *}$ & $.887^{* *}$ & $.891^{* *}$ & $.916^{* *}$ & $.897^{* *}$ & $.911^{* *}$ & $.902^{* *}$ \\
\hline $\mathrm{Z} 3$ & $.739^{* *}$ & $.775^{* *}$ & $.637^{* *}$ & $.859^{\circ *}$ & $.874^{* *}$ & $.878^{\circ *}$ & $.867^{\circ *}$ & $.827^{* *}$ & $.822^{* *}$ & $.894^{\circ *}$ & $.775^{* *}$ & $.874^{* *}$ & $.843^{* *}$ & $.886^{\circ *}$ & $.866^{\circ *}$ & $.862^{* *}$ & $.864^{* *}$ & $.895^{* *}$ & $.880^{\circ *}$ & $.886^{\circ *}$ & $.882^{\circ *}$ \\
\hline Z4 & $.760^{\circ *}$ & $.804^{* *}$ & $.634^{* *}$ & $.863^{* *}$ & $.910^{* *}$ & $.883^{\circ *}$ & $.875^{\circ *}$ & $.830^{\circ *}$ & $.846^{\circ *}$ & $.932^{* *}$ & $.771^{* *}$ & $.897^{* *}$ & $.860^{\circ *}$ & $.918^{* *}$ & $.901^{* *}$ & $.890^{\circ}$ & $.893^{* *}$ & $.921^{* *}$ & $.894^{* *}$ & $.912^{* *}$ & $.908^{* *}$ \\
\hline Z5 & $.742^{* *}$ & $.796^{\circ *}$ & $.586^{\circ *}$ & $.847^{* *}$ & $.909^{* *}$ & $.861^{\circ *}$ & $.865^{\circ *}$ & $.811^{* *}$ & $.831^{* *}$ & $.919^{\circ *}$ & $.745^{\circ *}$ & $.900^{* *}$ & $.837^{* *}$ & $.903^{* *}$ & $.895^{\circ *}$ & $.885^{* *}$ & $.886^{\circ *}$ & $.906^{* *}$ & $.884^{* *}$ & $.898^{* *}$ & $.899^{* *}$ \\
\hline Z6 & $.730^{* *}$ & $.762^{* *}$ & $.741^{* *}$ & $.876^{\circ *}$ & $.823^{* *}$ & $.904^{* *}$ & $.844^{\circ *}$ & $.869^{\circ *}$ & $.836^{\circ *}$ & $.887^{\circ *}$ & $.854^{* *}$ & $.859^{* *}$ & $.856^{* *}$ & $.872^{* *}$ & $.820^{\circ *}$ & $.823^{* *}$ & $.819^{\circ *}$ & $.876^{* *}$ & $.873^{* *}$ & $.861^{* *}$ & $.884^{* *}$ \\
\hline Z7 & $.743^{* *}$ & $.790^{\circ *}$ & $.628^{* 4}$ & $.871^{* *}$ & $.897^{\circ *}$ & $.866^{\circ *}$ & $.861^{* *}$ & $.833^{\circ *}$ & $.848^{* *}$ & $.920^{\circ *}$ & $.781^{* *}$ & $.895^{\circ *}$ & $.855^{\circ *}$ & $.891^{* *}$ & $.883^{\circ *}$ & $.869^{\circ *}$ & $.870^{\circ *}$ & $.898^{\circ *}$ & $.884^{* *}$ & $.887^{* *}$ & $.893^{* *}$ \\
\hline Z8 & $.725^{* *}$ & $.795^{* *}$ & $.583^{\circ *}$ & $846^{\circ *}$ & $909^{\circ *}$ & $.860^{\circ *}$ & $.864^{\circ *}$ & $.809^{* *}$ & $.824^{\circ *}$ & $.923^{\circ *}$ & $.741^{* *}$ & $.893^{* *}$ & $.842^{* *}$ & $.903^{\circ *}$ & $.898^{\circ *}$ & $.882^{\circ *}$ & $.889^{\circ *}$ & $.913^{* *}$ & $.883^{* *}$ & $.898^{\circ *}$ & $.892^{* *}$ \\
\hline Z9 & $.726^{\circ *}$ & $.778^{* *}$ & $.609^{\circ *}$ & $.870^{\circ *}$ & $.893^{* *}$ & $.864^{\circ *}$ & $.860^{\circ *}$ & $.808^{* *}$ & $.818^{* *}$ & $.906^{\circ *}$ & $.758^{* *}$ & $.889^{\circ *}$ & $.839^{\circ *}$ & $.891^{* *}$ & $.872^{\circ *}$ & $.866^{* *}$ & $.876^{\circ *}$ & $.908^{* *}$ & $.883^{* *}$ & $.885^{\circ *}$ & $.889^{\circ *}$ \\
\hline $\mathrm{Z} 10$ & $.735^{\circ *}$ & $.793^{* *}$ & $.681^{* *}$ & $.871^{* *}$ & $.878^{\circ *}$ & $.888^{\circ *}$ & $.863^{\circ *}$ & $.843^{\circ *}$ & $.842^{* *}$ & $.914^{\circ *}$ & $.800^{\circ *}$ & $.890^{\circ *}$ & $.850^{\circ *}$ & $.894^{* *}$ & $.876^{\circ *}$ & $.861^{\circ *}$ & $.861^{\circ *}$ & $.900^{\circ *}$ & $.894^{* *}$ & $.890^{\circ *}$ & $.897^{* *}$ \\
\hline Z11 & $.760^{\circ *}$ & $.804^{* *}$ & $.614^{* *}$ & $874^{* *}$ & $.910^{\circ *}$ & $.872^{\circ *}$ & $.876^{\circ *}$ & $.820^{\circ *}$ & $.833^{\circ *}$ & $.924^{* *}$ & $.762^{* *}$ & $.899^{* *}$ & $.856^{\circ *}$ & $.910^{* *}$ & $.898^{\circ *}$ & $.882^{\circ *}$ & $.895^{\circ *}$ & $.918^{\circ *}$ & $.894^{* *}$ & $.904^{* *}$ & $.897^{* *}$ \\
\hline $\mathrm{Z} 12$ & $.742^{* *}$ & $.788^{* *}$ & $.634^{\circ *}$ & $874^{\circ *}$ & $.897^{\circ *}$ & $.884^{\circ *}$ & $.869^{* *}$ & $.827^{* *}$ & $.832^{* *}$ & $.912^{* *}$ & $.780^{\circ *}$ & $.891^{\circ *}$ & $.853^{* *}$ & $.904^{* *}$ & $.878^{\circ *}$ & $.864^{* *}$ & $.868^{\circ *}$ & $.913^{* *}$ & $.892^{* *}$ & $.895^{* *}$ & $.894^{* *}$ \\
\hline Z13 & $.743^{\circ *}$ & $.797^{* *}$ & $.669^{* *}$ & $.872^{* *}$ & $.875^{* *}$ & $.889^{\circ *}$ & $.857^{\circ *}$ & $.851^{\circ *}$ & $.834^{* *}$ & $.908^{* *}$ & $.809^{\circ *}$ & $.878^{\circ *}$ & $.861^{* *}$ & $.900^{\circ *}$ & $.864^{\circ *}$ & $.851^{* *}$ & $.856^{\circ *}$ & $.900^{\circ *}$ & $.884^{\circ *}$ & $.885^{\circ *}$ & $.889^{\circ *}$ \\
\hline Z14 & $.757^{* *}$ & $.805^{* *}$ & $.638^{* *}$ & $.871^{* *}$ & $.901^{* *}$ & $.881^{\circ *}$ & $.871^{\circ *}$ & $.831^{\circ *}$ & $.846^{\circ *}$ & $.920^{\circ *}$ & $.782^{* *}$ & $.898^{* *}$ & $.860^{\circ *}$ & $.910^{* *}$ & $.888^{\circ *}$ & $.874^{* *}$ & $.877^{* *}$ & $.918^{\circ *}$ & $.889^{\circ *}$ & $.902^{* *}$ & $.903^{* *}$ \\
\hline $\mathrm{Z} 15$ & $.729^{* *}$ & $.790^{\circ *}$ & $.642^{* *}$ & $.875^{* *}$ & $.889^{\circ *}$ & $.887^{\circ *}$ & $.867^{\circ *}$ & $.832^{* *}$ & $.843^{* *}$ & $.915^{\circ *}$ & $.801^{* *}$ & $.890^{\circ *}$ & $.859^{* *}$ & $.901 *$ & $.875^{\circ *}$ & $.866^{\circ *}$ & $.867^{* *}$ & $.910^{\circ *}$ & $.891^{1 *}$ & $.895^{\circ *}$ & $.897^{* *}$ \\
\hline $\mathrm{Z} 16$ & $.711^{* *}$ & $.773^{* *}$ & $.595^{* *}$ & $.854^{* *}$ & $.896^{\circ *}$ & $.857^{\circ *}$ & $.853^{\circ *}$ & $.801^{\circ *}$ & $.818^{* *}$ & $.906^{\circ *}$ & $.756^{* *}$ & $.880^{\circ *}$ & $.836^{\circ *}$ & $.889^{\circ *}$ & $.873^{\circ *}$ & $.860^{\circ *}$ & $.865^{\circ *}$ & $.899^{* *}$ & $.867^{\circ *}$ & $.876^{\circ *}$ & $.876^{*}$ \\
\hline \multicolumn{22}{|c|}{ **. Significant correlation at. 01 level (two tails) } \\
\hline \multicolumn{22}{|c|}{ TABLE 12 RESULTS OF SHAPLEY VALUE ANALYSIS BASED ON THE REGRESSION EQUATION } \\
\hline $\begin{array}{c}\text { Results of } \\
\text { Shapley } \\
\text { value } \\
\text { analysis }\end{array}$ & Y1 & Y2 & Y3 & Y4 & Y5 & Y6 & Y7 & Y8 & Y9 & Y10 & Y11 & Y12 & Y13 & Y14 & Y15 & Y16 & Y17 & Y18 & Y19 & $\mathrm{Y} 20$ & Y21 \\
\hline $\begin{array}{l}\mathrm{Z} 1 \\
\mathrm{Z} 2 \\
\mathrm{Z} 3 \\
\mathrm{Z} 4 \\
\mathrm{Z} 5 \\
\mathrm{Z} 6\end{array}$ & $\begin{array}{l}.431^{* *} \\
.451^{*} \\
.455^{*}\end{array}$ & $\begin{array}{l}.569^{* *} \\
.549^{*} \\
.545^{*}\end{array}$ & $.338^{* *}$ & & $.134^{* *}$ & $.662^{* *}$ & $\begin{array}{l}.120^{* *} \\
.187^{* *}\end{array}$ & & & & & $.118^{* *}$ & & & & $\begin{array}{l}.115^{* *} \\
.195^{* *}\end{array}$ & & $\begin{array}{l}.139^{* *} \\
.222^{* *}\end{array}$ & $\begin{array}{l}.120^{* *} \\
.194^{* *}\end{array}$ & $\begin{array}{l}.129^{* *} \\
.202^{* *}\end{array}$ & $.126^{* *}$ \\
\hline $\begin{array}{l}\text { Z7 } \\
\text { Z8 }\end{array}$ & & & $.031^{*}$ & $\begin{array}{l}.056^{*} \\
.292^{*}\end{array}$ & $\begin{array}{l}.060^{* *} \\
373^{* *}\end{array}$ & $.055^{* *}$ & $.055^{\circ *}$ & $.044^{* *}$ & $.045^{* *}$ & $.084^{* *}$ & $.039^{* *}$ & $.056^{*}$ & $.051^{* *}$ & $.054^{* *}$ & $.054^{* *}$ & $.050^{* *}$ & $.051^{* *}$ & $.055^{* *}$ & $.054^{* *}$ & $.052^{* *}$ & $.055^{*}$ \\
\hline $\mathrm{Zg}$ & & & & $.257^{* *}$ & $271^{* *}$ & & $.229^{* *}$ & & & & & & & & & & & & & & \\
\hline $\begin{array}{l}\mathrm{Z} 10 \\
\mathrm{Z} 11\end{array}$ & & & $114^{* *}$ & $.345^{* *}$ & $341^{* *}$ & & & & & & & & & & & & $314^{* *}$ & & & & \\
\hline $\begin{array}{l}Z 11 \\
\mathrm{Z} 12\end{array}$ & & & .114 & 281 & $.267^{* *}$ & & $233^{* *}$ & & & & & $.258^{* *}$ & & & $.242^{*}$ & & & & & & \\
\hline $\begin{array}{l}Z 13 \\
\text { Z14 }\end{array}$ & & & & & & & & & $.174^{* *}$ & $.268^{* *}$ & $.164^{* *}$ & $.206^{*}$ & $.189^{* *}$ & & & & & & $235 *$ & & \\
\hline Z15 & & & & & & & & & & & & & & & & & & $.517^{* *}$ & .235 & $.483^{*}$ & .248 \\
\hline Z16 & & & & & & & & & & & & & & & & & & & $323^{* *}$ & $.339^{* *}$ & $.338^{* *}$ \\
\hline
\end{tabular}

Through the above correlation analysis and the application of the Shapley value decomposition method based on the regression equation, a full path map of the

transformation path of the internal quality demand of cigarette consumers is finally constructed (see Figure 5 below).

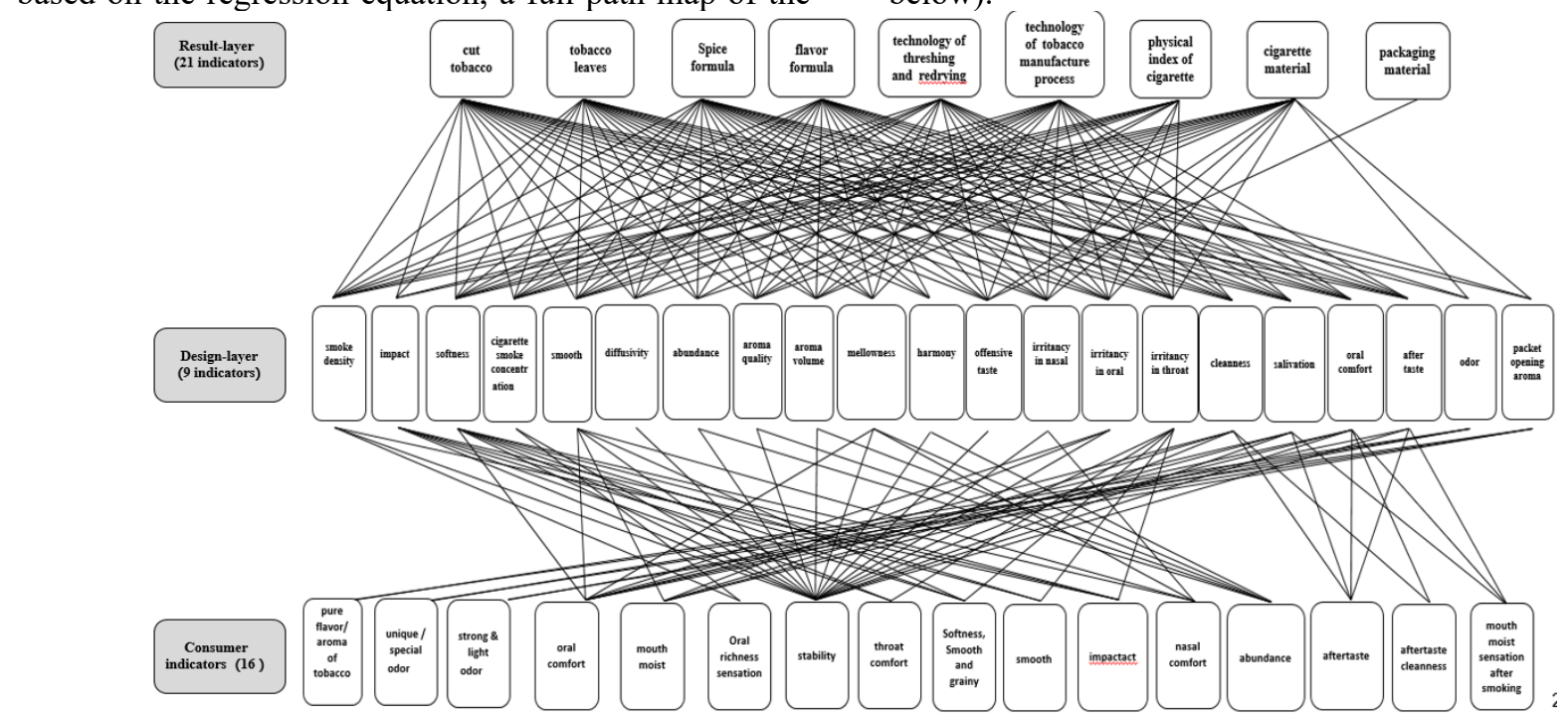

FIGURE 5. TRANSFORMATION FULL PATH DIAGRAM: DESIGN-LAYER -> RESULT-LAYER -> CONSUMER
From table 12, it can be concluded that resolving the collinearity between independent variables can more accurately explain the importance of Result-layer indicators for consumer indicators in this project. To determine the contribution of the indicator. 
In order to simplify the full path graph, this paper selects the indicator with the highest average correlation to build the full path graph of Figure 6, that is, there is only one most relevant path for the transformation from a single consumer indicator to the result-layer and then to the design-layer.
Among them, the indicator coefficient from consumer indicator to result-layer is the weight coefficient obtained by quantitative research, and the indicator coefficient from the result-layer to design-layer is the weight coefficient obtained by the expert workshop.

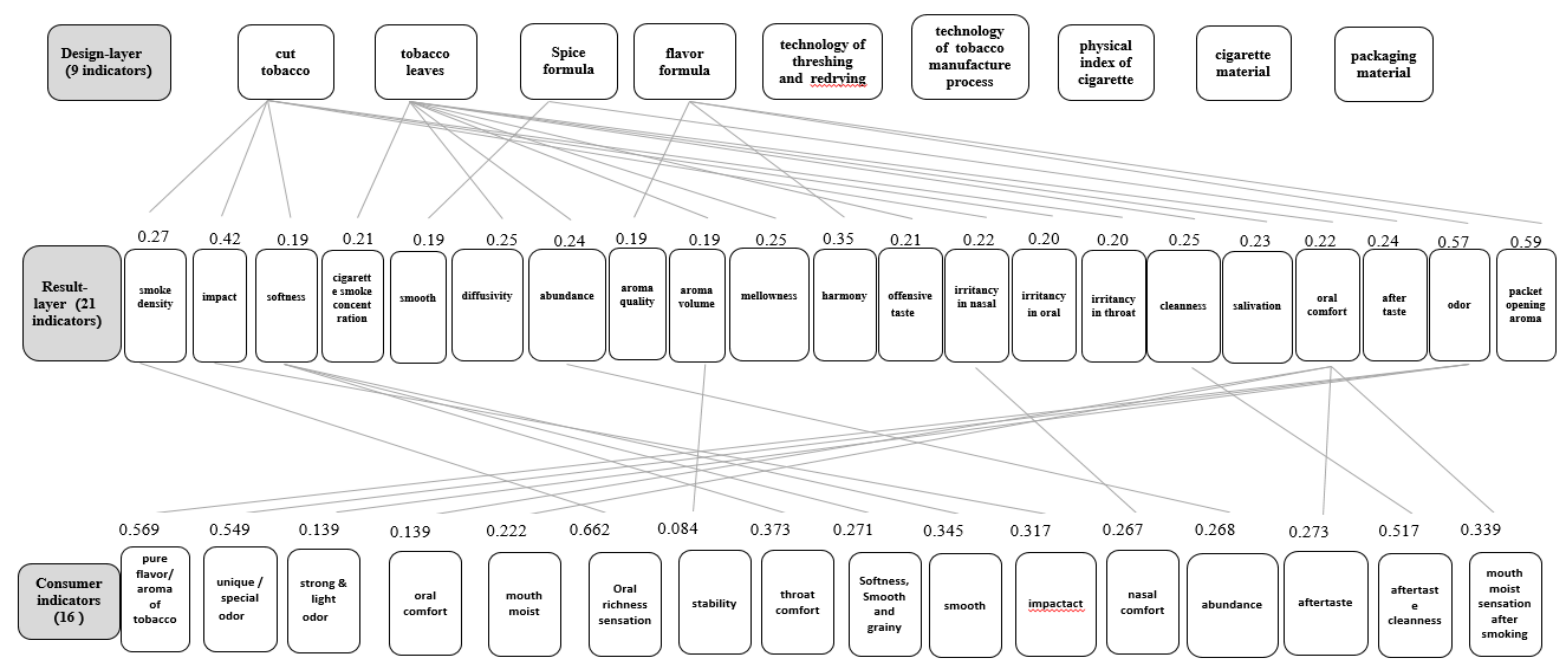

FIGURE 6. TRANSFORMATION PATH CHART: DESIGN-LAYER -> RESULT-LAYER -> CONSUMER (ONLY THE HIGHEST AVERAGE CORRELATION INDICATOR IS SELECTED)

\section{CONCLUSION}

A. According to the final construction of the transformation path, we can get the expert technical indicators that directly affect consumers' evaluation of the internal quality of cigarettes and the technical indicators related to these expert technical indicators of cigarette manufacturing. At the same time, we can accurately get the influence degree of these product attribute design factors on the sensory quality evaluation results of consumers through the correlation coefficient value.

$B$. If the transformation path with the highest weight is selected, the conversion path from 16 consumer evaluation indicators to expert technical indicators and then to relevant indicators of cigarette manufacturing technology can be obtained: pure flavor/aroma of tobacco - packet opening aroma - flavor formula; unique / special odor - packet opening aroma - flavor formula; strong \& light odor - packet opening aroma - flavor formula; oral comfort- cleanliness - tobacco leaves; mouth moist - Cleanliness - tobacco leaves; Oral richness sensation - cigarette smoke concentration tobacco leaves; stability - aroma quality - flavor formula; throat comfort - softness - cut tobacco; Softness ,Smooth and grainy - softness - cut tobacco; smooth - impact - cut tobacco; impact- softness- cut tobacco; nasal comfortsoftness- cut tobacco, abundance-aroma quality- flavor formula, after taste sweetness and comfortable-cleanliness-tobacco leaves; aftertaste cleanness-cleanliness-tobacco leaves; mouth moist sensation after smoking- oral comfort-tobacco leaves.

$C$. In this paper, through the form of a workshop, the technical indicators of cigarette products, the indicators of experts' attention, and the indicators of consumer demand are correlated and verified. The docking transformation mode of cigarette product characteristics and consumer demand is established. Through the combination of the consumption evaluation system and expert cigarette evaluation indicator, a real complete path of "consumer feedback consumer demand $<->$ transformation expert evaluation indicator $<->$ correspondence product technology improvement" is established. For product R\&D personnel to understand consumer demand, convert it into product $\mathrm{R} \& \mathrm{D}$ and maintenance objectives, further accurately guide formula, conduct product $R \& D$, and Maintenance is of great significance.

\section{ACKNOWLEDGMENTS}

This project was supported financially by the Basic Research Foundation of Yunnan Tobacco Industry Co. Ltd. "Research on the conceptual design of product innovation based on cross-border thinking" (2017cp05) and the Basic Research Foundation of Yunnan Tobacco Industry Co. Ltd. "Construction and application of R\&D information platform based on market demand orientation" (2019xx01).

\section{REFERENCE}

[1] YC / t497-2014 sensory evaluation method for Chinese style cigarettes Part 4: sensory technical requirements for cigarettes (gb5606.4-2005)

[2] Saaty T L. Axiomatic foundation of the analytic hierarchy process [J]. Management Science,1986,32(7) : 841-855.

[3] Qi Yulong, research on performance appraisal system based on AHP, Journal of Xi'an University of engineering. 2008.22 (3): 125-128

[4] Xie Xuanzheng; application of AHP in performance management [J]. China labor; 2005 (11): 72-74

[5] Zhu Jun. Research on credit system construction of the tobacco industry [D]. Tianjin: Tianjin University, 2006 
[6] Zheng Xiaoping, Zhou Quan, Liu Yiling. Study on the dynamic credit evaluation model of tobacco monopoly retail operators based on AHP [J]. Chongqing and the world (Academic Edition), 2016 (11): 7-11

[7] He Ruhan, Wan Fangming, Xiang Lishuang, et al. Construction of a credit index system for retail cigarette customers based on group decision and AHP [J]. Computer application and software, $12: 81-86,2019(36)$
[8] Yang Lei, Yang Qianxu, Feng Hongtao, et al. An Empirical Study on the influencing factors of cigarette consumer satisfaction [J]. Journal of Yunnan Agricultural University, 2019, 13 (5): 93-101

[9] Qiu Chongbao, Xu Xiaoming, Guo Hongwu, et al. The application of AHP in determining the weight of the tobacco performance evaluation index [J]. China new technology and new products, 2016 (2): 156-157. 